\title{
Development of Simultaneous
} HPLC-Fluorescence Assay of Phenol and Chlorophenols in Tap Water after Pre-Column Derivatization with 3-Chlorocarbonyl-6,7-dimethoxy-1-
methyl-2(1H)-quinoxalinone

\author{
Yasuhiko Higashi \\ Department of Analytical Chemistry, Faculty of Pharmaceutical Sciences, Hokuriku University, Kanazawa, Japan \\ Email: y-higashi@hokuriku-u.ac.jp
}

Received 27 November 2015; accepted 4 January 2016; published 7 January 2016

Copyright (C) 2016 by author and Scientific Research Publishing Inc.

This work is licensed under the Creative Commons Attribution International License (CC BY). http://creativecommons.org/licenses/by/4.0/ c) (i) Open Access

\section{Abstract}

Chlorophenols (2-chlorophenol, 4-chlorophenol, 2,4-dichlorophenol, 2,6-dichlorophenol and 2,4, 6-trichlorophenol) may be presented in natural waters or drinking water as a result of disinfection processes involving chlorination, or as contaminants derived from domestic products, industrial operations and agricultural chemicals. A previous HPLC-UV method for determination of phenol and five chlorophenols in tap water using 4-fluoro-7-nitro-2,1,3-benzoxadiaole as a UV labeling reagent shows limited sensitivity. Here, we present an improved HPLC-fluorescence detection method for simultaneous determination of phenol and the above chlorophenols in tap water after pre-column derivatization with 3-chlorocarbonyl-6,7-dimethoxy-1-methyl-2(1H)-quinoxalinone (DMEQ-COCl), using a short, narrow column $(50 \times 2.1 \mathrm{~mm}$ i.d., packed with $5 \mu \mathrm{m}$ particles of $\mathrm{C}_{18}$ material) to improve the sensitivity. Standard samples containing the compounds are derivatized with DMEQ-COCl in borate buffer (pH 9.0) at room temperature for 3 mins. The response is linear in the concentration range of $0.01-0.05$ to $0.5 \mathrm{mg} / \mathrm{L}$ with $r^{2}$ values $\geq 0.9967$ for all compounds. The lower limits of detection are 0.001 to $0.008 \mathrm{mg} / \mathrm{L}$, and the coefficients of variation are less than $8.8 \%$. The recovery values from tap water spiked with standard samples are satisfactory. The present method is suitable for examining whether or not tap water samples are contaminated with phenol and chlorophenols in excess of regulatory values. 


\section{Keywords}

\section{Phenol, Chlorophenol, Fluorescence, Derivatization, 3-Chlorocarbonyl-6,7-dimethoxy-1-methyl-2(1H)-quinoxalinone}

\section{Introduction}

In order to confirm the quality and safety of potable water, it is essential to evaluate levels of pollutants. Phenol is a ubiquitous pollutant in the aquatic environment because of its widespread use in the synthesis of dyes and drugs in the chemical industry and its presence in commercial products used in daily life. Five chlorophenols (2-chlorophenol, 4-chlorophenol, 2,4-dichlorophenol, 2,6-dichlorophenol, and 2,4,6-trichlorophenol) are also presented in drinking water as a result of disinfection by means of chlorination, as well as being formed by the reaction of hypochlorite (used as a bleach and disinfectant) with phenolic acids and via the degradation of phenoxy herbicides [1].

The World Health Organization (WHO) guideline value for 2,4,6-trichlorophenol is $0.2 \mathrm{mg} / \mathrm{L}$ and concentrations of chlorophenols in drinking-water are usually less than $0.001 \mathrm{mg} / \mathrm{L}$ [1]. The maximum permissible level of total phenols is $0.5 \mathrm{mg} / \mathrm{L}$ in drinking water, but concentration of individual phenols must not exceed $0.1 \mathrm{mg} / \mathrm{L}$ according to United States Environmental Protection and European Union guidelines [2]-[4]. On the other hand, the maximum permissible level of total phenols according to the Japanese Water Pollution Control Law is less than $0.005 \mathrm{mg} / \mathrm{L}$ in drinking and tap water and less than $5 \mathrm{mg} / \mathrm{L}$ in industrial waste water. A widely used analytical method for determination of total phenols in water samples is visible absorbance measurement after reaction with 4-aminoantipyrine [5] [6]. However, this method cannot determine the concentrations of individual phenols. Various separation methods for phenols have been reported, employing GC, HPLC, and capillary electrophoresis with several detection modes, such as fluorimetry, mass spectrometry, chemiluminescence, and electrochemical analysis [7]-[12].

Derivatization with a UV absorber or a fluorescent compound that can react with a functional group of the target compound(s) is one of the most useful strategies to obtain high selectivity and sensitivity. Phenol in river water and wine has been determined by means of HPLC-UV after derivatization with benzoyl chloride, and simultaneous analysis of phenol and chlorophenols in urine has been achieved by means of HPLC with fluorescence detection (FLD) after derivatization with 4-(4,5-diphenyl-1H-imidazol-2-yl) benzoyl chloride, though this method requires sample pretreatment [4] [13]. There is also a report describing HPLC-fluorescence detection after derivatization with coumarin-6-sulfonyl chloride for determining phenol and chlorophenols in various environmental waters, with sample clean-up by means of filtration [10].

Since it is very important to quickly check and confirm the quality of water throughout the world, we set out to develop a sensitive and selective method for simultaneous determination of phenol and chlorophenols without any clean-up step. 4-Fluoro-7-nitro-2,1,3-benzoxadiazole (NBD-F) has been used for HPLC-FLD as a fluorescent label reactive with primary and secondary amino groups [14]-[18]. Toyo'oka et al. also used NBD-F as a UV labeling reagent for the phenolic hydroxyl group of $N$-acetyltyrosine [19]. Subsequently, an HPLC-UV determination of phenol and five chlorophenols is developed using NBD-F for the analysis of tap water without sample clean-up [20], but its sensitivity is limited (0.004 to $0.1 \mathrm{mg} / \mathrm{L}$ ).

Here, we present a sensitive HPLC-FLD method for simultaneous determination of phenol and five chlorophenols in tap water after pre-column derivatization with 3-chlorocarbonyl-6,7-dimethoxy-1-methyl-2(1H)quinoxalinone (DMEQ-COCl; Figure 1), without the need for sample clean-up. The use of a narrow, short analysis column is helpful to increase peak sharpness, which contributes to improving the sensitivity.

\section{Materials and Methods}

\subsection{Materials}

Phenol, 2-chlorophenol, 4-chlorophenol, 2,4-dichlorophenol, 2,6-dichlorophenol, 2,4,6-trichlorophenol, DMEQ$\mathrm{COCl}$, and general reagents were obtained from Wako Pure Chemical Industries (Osaka, Japan). Tap water was collected from the laboratory supply. 
<smiles>[R]c1cc([R])c(O)c([R])c1</smiles>

Phenol and chlorphenols

DMEQ-COCl<smiles>[R]c1cc([R])c(OC(=O)c2nc3cc(OC)c(OC)cc3n(C)c2=O)c([R])c1</smiles>

DMEQ Derivative

Figure 1. Derivatization of phenol and chlorophenols with DMEQ-COCl. Phenol: $\mathrm{R}_{1}=\mathrm{R}_{2}=\mathrm{R}_{3}=\mathrm{H}$; 2-Chlorophenol: $\mathrm{R}_{1}=$ Cl, $\mathrm{R}_{2}=\mathrm{R}_{3}=\mathrm{H}$; 4-Chlorophenol: $\mathrm{R}_{1}=\mathrm{R}_{2}=\mathrm{H}, \mathrm{R}_{3}=\mathrm{Cl}$; 2,4-Dichlorophenol: $\mathrm{R}_{1}=\mathrm{R}_{2}=\mathrm{Cl}, \mathrm{R}_{3}=\mathrm{H}$; 2,6-Dichlorophenol: $\mathrm{R}_{1}=$ $\mathrm{R}_{3}=\mathrm{Cl}, \mathrm{R}_{2}=\mathrm{H} ;$ 2,4,6-Trichlorophenol: $\mathrm{R}_{1}=\mathrm{R}_{2}=\mathrm{R}_{3}=\mathrm{Cl}$.

\subsection{Chromatographic Conditions}

The HPLC system comprised a model L-6200 pump (Hitachi, Tokyo, Japan), a Rheodyne injection valve (Cotati. CA, USA) with a $20-\mu \mathrm{L}$ loop, and a model RF-10A $\mathrm{XL}_{\mathrm{XL}}$ fluorescence detector (Shimadzu, Kyoto, Japan) operating at an excitation wavelength of $400 \mathrm{~nm}$ and emission wavelength of $500 \mathrm{~nm}$. The HPLC column (Inertsil ODS-4, GL Science Inc., Kyoto) was $50 \times 2.1 \mathrm{~mm}$ i.d., packed with $5 \mu \mathrm{m}$ particles of $\mathrm{C}_{18}$ material. Quantification of the peaks was performed using a Chromatopac Model C-R3A integrator (Shimadzu). The mobile phase was prepared by the addition of acetonitrile $(320 \mathrm{~mL})$ to a solution of $680 \mathrm{~mL}$ containing trifluoroacetic acid $(0.1 \mathrm{v} / \mathrm{v} \%)$ in ultrapure water (Milli-Q water purification system, Simplicity ${ }^{\circledR} \mathrm{UV}$, Millipore Corporation, Bedford, MA, USA). The samples were eluted from the column at room temperature at a flow rate of $0.5 \mathrm{~mL} / \mathrm{min}$.

\subsection{Derivatization}

Standard samples of phenol and chlorophenols were dissolved in ultrapure water and acetone, respectively, and adjusted to the concentration of $1 \mathrm{~g} / \mathrm{L}$. The standard mixture was diluted with ultrapure water. Borate buffer (0.1 M) was adjusted to $\mathrm{pH} 9.0$ by the addition of $\mathrm{NaOH}$. Borate buffer $(100 \mu \mathrm{L})$ was added to diluted standard samples $(100 \mu \mathrm{L}$, containing $0,0.01,0.02,0.05,0.1,0.2$, or $0.5 \mathrm{mg} / \mathrm{L}$ of each compound). DMEQ-COCl solution in acetonitrile ( $2 \mathrm{mg} / \mathrm{mL}, 100 \mu \mathrm{L}$ ) was added and vortexed. The mixture was allowed to react for $3 \mathrm{~min}$ at room temperature. Saturated L-aspartate solution $(100 \mu \mathrm{L})$ was added to stop the reaction, and aliquots $(10 \mu \mathrm{L})$ were injected into the HPLC system.

\subsection{Application to Water Samples}

Water samples spiked with standard samples (lower limit of quantification, $0.05,0.1,0.2$, or $0.5 \mathrm{mg} / \mathrm{L}$ of each compound) were passed through $0.45 \mu \mathrm{m}$ filters (Cosmonice Filter S, Nacalaitesque) to remove suspended substances and immediately analyzed. Filtration was confirmed to have no effect on the analysis by analyzing a sample spiked with standards before and after filtration; no significant difference in recovery was observed.

\subsection{Relative Recovery}

Relative recovery was expressed as the ratio of the slope of the calibration curve prepared from a water sample spiked with standard sample to the slope of the standard calibration curve prepared as described above. Relative recovery data were used to assess the accuracy of the method.

\section{Results and Discussion}

\subsection{Derivatization of Phenol and Five Chlorophenols with DMEQ-COCl}

For the time course study, the reaction time was set at 2, 3, 5, 10, and 15 min. Phenol and five chlorophenols (100 $\mu \mathrm{L}$, each $0.1 \mathrm{mg} / \mathrm{L})$, borate buffer (100 $\mu \mathrm{L}$, pH 9.0)and DMEQ-COCl (100 $\mu \mathrm{L}, 2 \mathrm{mg} / \mathrm{mL})$ were mixed as described in Materials and Methods. The maximum peak area or plateau level was reached within 3 mins (Figure 2).

Next, pH dependency (pH 7.5 to 10.0) was examined at the derivatization time of 3 min (Figure 3). Peak areas of DMEQ-phenol and DMEQ-4-chlorophenol at pH 7.5 were $33 \%$ and $82 \%$ of the maximum area, respectively. The peak areas of all DMEQ derivatives tended to be decreased at $\mathrm{pH} 10.0$. However, the peak areas of 


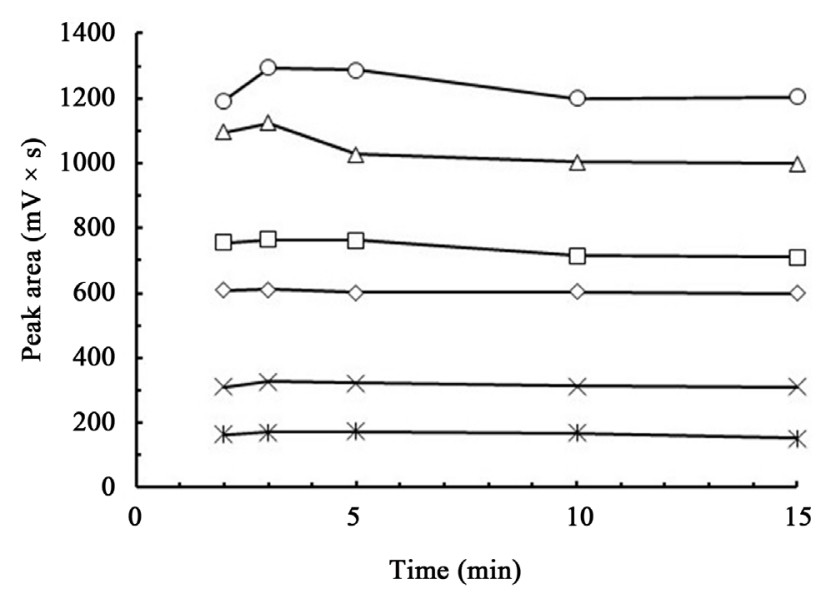

Figure 2. Time courses of formation of the derivatives of phenol and chlorophenols with DMEQ-COCl. Standard sample (containing each compound $0.1 \mathrm{mg} / \mathrm{L}$ ) was allowed to react with DMEQ-COCl in borate buffer at pH 9.0. (०), DMEQ-phenol; $(\Delta)$, DMEQ-4-chlorophenol; $(\square)$, DMEQ-2-chlorophenol; $(\diamond)$, DMEQ-2,4-dichlorophenol; $(\times)$, DMEQ-2,6-dichlorophenol; $(*)$, DMEQ-2,4,6-trichlorophenol.

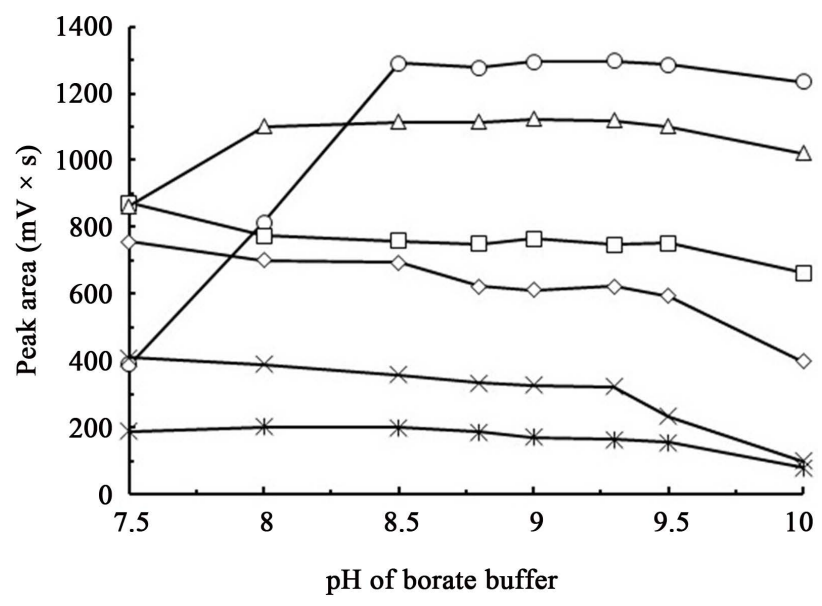

Figure 3. pH Dependency of formation of the derivatives of phenol and chlorophenols with DMEQ-COCl. Standard sample (containing each compound $0.1 \mathrm{mg} / \mathrm{L}$ ) was allowed to react with DMEQ-COCl in borate buffer at various $\mathrm{pH}$ values. (०), DMEQ-phenol; $(\Delta)$, DMEQ-4-chlorophenol; ( $\square)$, DMEQ-2-chlorophenol; $(\diamond)$, DMEQ-2,4-dichlorophenol; $(\times)$, DMEQ-2,6-dichlorophenol; (*), DMEQ-2,4,6-trichlorophenol.

all compounds were stable (more than $95 \%$ of the maximum area) in the range of $\mathrm{pH} 8.5$ to $\mathrm{pH}$ 9.3.Since, under $\mathrm{pH}$ 8.5, it is guessed that a little $\mathrm{pH}$ change may effect phenol detection, simultaneous determination of tested compounds is not better at $\mathrm{pH} 8.5$.

In preliminary tests (data not shown), the peak areas of all derivatives obtained with $1 \mathrm{mg} / \mathrm{mL}$ of DMEQ$\mathrm{COCl}$ at $\mathrm{pH} 9.0$ and room temperature were less than about $60 \%$ of the control. Furthermore, when using 3 $\mathrm{mg} / \mathrm{mL}$ of DMEQ-COCl, a large blank peak interfered with the peaks of phenol, 2-chlorophenol, and 4-chlorophenol. Thus, the derivatization time of $3 \mathrm{~min}$ at $\mathrm{pH}$ 9.0using $2 \mathrm{mg} / \mathrm{mL}$ of DMEQ-COCl was chosen for the assay.

\subsection{Chromatogram}

Figure 4 shows typical chromatograms obtained from (A) blank and (B) standard sample $(0.1 \mathrm{mg} / \mathrm{L})$. In the analysis, full scale (128 mV) was automatically shifted to $64 \mathrm{mV}$ at 20 min to clearly observe the DMEQ-2,4,6trichlorophenol peak. The retention times of DMEQ-phenol, DMEQ-2-chlorophenol, DMEQ-4-chlorophenol, 


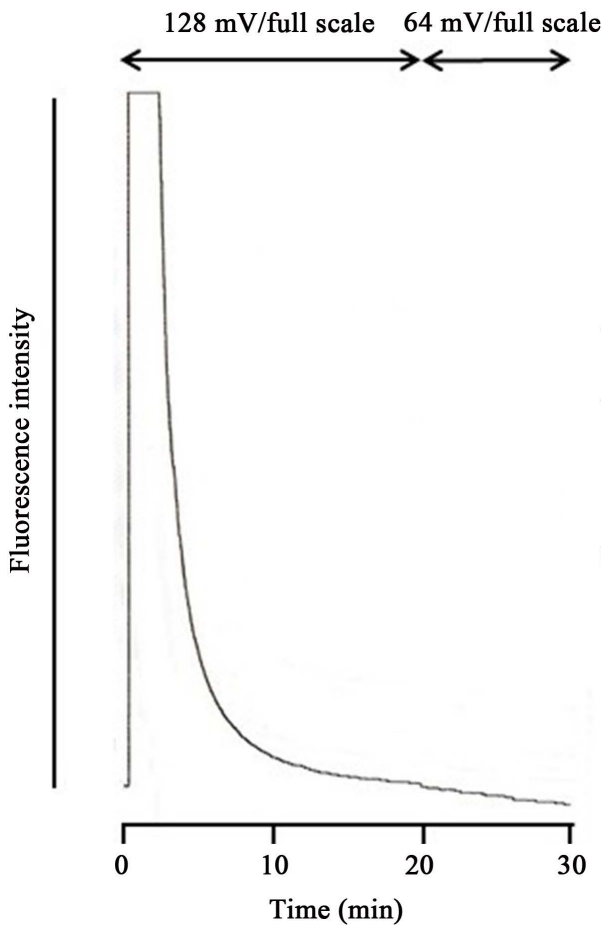

(a)

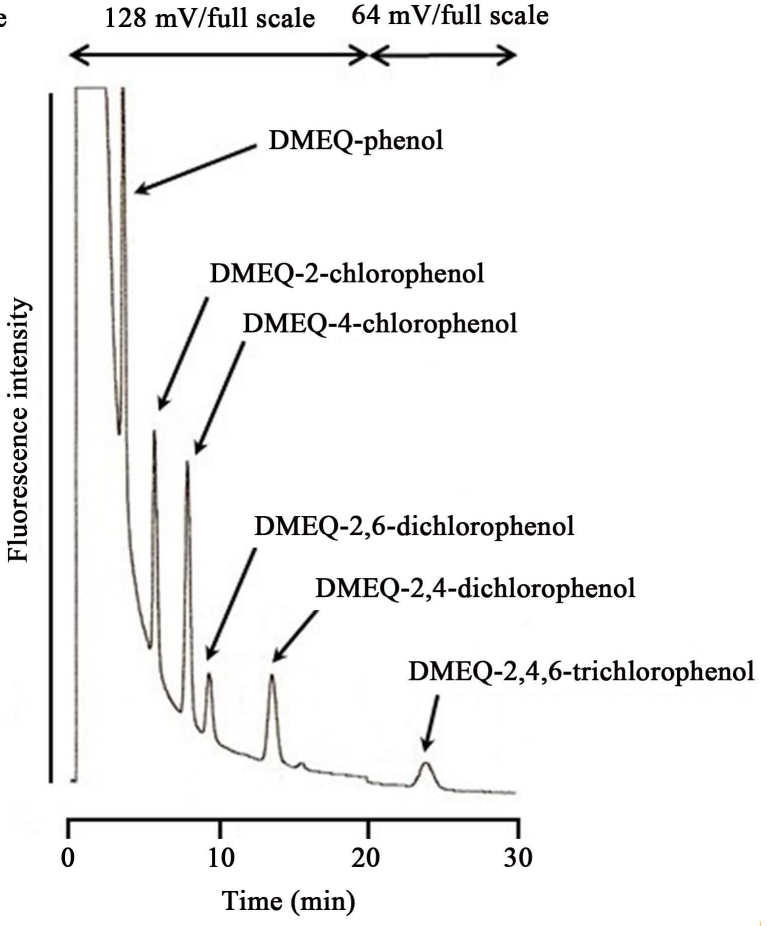

(b)

Figure 4. Typical chromatograms of blank (a) and standard samples (b) after derivatization with DMEQ-COCl. Standard sample (containing each compound $0.1 \mathrm{mg} / \mathrm{L}$ ) was allowed to react with DMEQ-COCl for 3 mins at pH 9.0. Retention times (min): 3.6 DMEQ-phenol; 5.7, DMEQ-2-chlorophenol; 7.9, DMEQ-4-chlorophenol; 9.3, DMEQ-2,6-dichlorophenol; 13.6, DMEQ-2,4-dichlorophenol; 23.9, DMEQ-2,4,6-trichlorophenol. Fill scale was automatically shifted to $64 \mathrm{mV}$ at $20 \mathrm{mins}$.

DMEQ-2,6-dichlorophenol, DMEQ-2,4-dichlorophenol, and DMEQ-2,4,6-trichlorophenol were 3.6, 5.7, 7.9, 9.3, 13.6, and $23.9 \mathrm{~min}$, respectively. The running time was 30 mins.

\subsection{Standard Curves of Phenol and Five Chlorophenols}

The standard curves of phenol, 2-chlorophenol, 4-chlorophenol, 2,6-dichlorophenol, 2,4-dichlorophenol, and 2,4,6-trichlorophenol were constructed by plotting integrated peak areas of derivatives vs. concentrations of phenolic compounds. The calibration data are summarized in Table 1 . The plots were linear in the concentration range of $0.01-0.05$ to $0.5 \mathrm{mg} / \mathrm{L}$, with $r^{2}$ value $\geq 0.9967$ for all compounds. The values of the lower limit of quantification were taken as the lowest concentration on the standard curve. The lower limits of detection for phenol and 2-chlorophenol were estimated as the concentrations giving a detectable peak, since these peaks were located close to a large blank peak. The lower limits of detection for 4-chlorophenol, 2,4-dichlorophenol, 2,6-dichlorophenol, and 2,4,6-trichlorophenol were taken to be the concentrations giving a signal-to-noise ratio of 3:1. The lower limits of detection for phenol, 2-chlorophenol, 4-chlorophenol, 2,4-dichlorophenol, 2,6dichlorophenol, and 2,4,6-trichlorophenol were $0.003,0.002,0.001,0.004,0.002$, and $0.008 \mathrm{mg} / \mathrm{L}$, respectively (range of 0.0025 to $0.020 \mathrm{ng} / 20 \mu \mathrm{L}$ injection as absolute amount).

The method using NBD-F previously developed in our laboratory showed relatively poor sensitivity [20]. The present method shows 1.2- to 5-fold greater sensitivity in terms of the lower limits of detection (8.5- to 33-fold improvement in terms of absolute amount).

\subsection{Precision and Accuracy}

Precision and accuracy for intra-day and inter-day assays of these derivatives are shown in Table 2 and Table 3. In the intra-day assay, the range of standard deviation was within $2.7 \%$ to $8.0 \%$. The recoveries were within $96.5 \%$ to $104.2 \%$. In the inter-day assay, the range of standard deviation was within $4.3 \%$ to $8.9 \%$, and the recoveries were within $95.5 \%$ to $105.0 \%$. 
Table 1. Linear correlation parameters.

\begin{tabular}{|c|c|c|c|c|c|}
\hline Compounds & Slope & Intercept & Concentration range & $r^{2}$ & Lower limit of detection $(\mathrm{S} / \mathrm{N}=3)$ \\
\hline Phenol & 12,057 & +50.61 & 0.01 to $0.5 \mathrm{mg} / \mathrm{L}$ & 0.9995 & $0.003 \mathrm{mg} / \mathrm{L}\left(0.0075^{*}\right)$ \\
\hline 2-Chlorophenol & 8892 & -88.43 & 0.01 to $0.5 \mathrm{mg} / \mathrm{L}$ & 0.9982 & $0.002 \mathrm{mg} / \mathrm{L}\left(0.0050^{*}\right)$ \\
\hline 4-Chlorophenol & 10,422 & +43.71 & 0.01 to $0.5 \mathrm{mg} / \mathrm{L}$ & 0.9984 & $0.001 \mathrm{mg} / \mathrm{L}\left(0.0025^{*}\right)$ \\
\hline 2,6-Dichlorophenol & 2799 & +41.28 & 0.02 to $0.5 \mathrm{mg} / \mathrm{L}$ & 0.9967 & $0.004 \mathrm{mg} / \mathrm{L}\left(0.010^{*}\right)$ \\
\hline 2,4-Dichlorophenol & 5315 & +46.36 & 0.01 to $0.5 \mathrm{mg} / \mathrm{L}$ & 0.9990 & $0.002 \mathrm{mg} / \mathrm{L}\left(0.0050^{*}\right)$ \\
\hline 2,4,6-Trichlorophenol & 1555 & +18.95 & 0.05 to $0.5 \mathrm{mg} / \mathrm{L}$ & 0.9972 & $0.008 \mathrm{mg} / \mathrm{L}\left(0.020^{*}\right)$ \\
\hline
\end{tabular}

${ }^{*}:$ Data are expressed as absolute amount (ng/20 $\mu \mathrm{L}$ injection).

Table 2. Intra-day assay reproducibility for determination of phenol and chlorophenols

\begin{tabular}{|c|c|c|c|}
\hline Compounds (mg/L) & Measured (mg/L, Mean \pm S.D., $n=5)$ & C.V. (\%) & Recovery (\%) \\
\hline \multicolumn{4}{|l|}{ Phenol } \\
\hline 0.02 & $0.0193 \pm 0.0015$ & 8.0 & 96.5 \\
\hline 0.1 & $0.0972 \pm 0.0052$ & 5.4 & 97.2 \\
\hline 0.5 & $0.516 \pm 0.021$ & 4.1 & 103.2 \\
\hline \multicolumn{4}{|l|}{ 2-Chlorophenol } \\
\hline 0.02 & $0.0204 \pm 0.0016$ & 7.8 & 102.0 \\
\hline 0.1 & $0.0998 \pm 0.0064$ & 6.4 & 99.8 \\
\hline 0.5 & $0.512 \pm 0.019$ & 3.7 & 102.4 \\
\hline \multicolumn{4}{|l|}{ 4-Chlorophenol } \\
\hline 0.02 & $0.0198 \pm 0.0014$ & 7.0 & 99.0 \\
\hline 0.1 & $0.102 \pm 0.006$ & 5.9 & 102.0 \\
\hline 0.5 & $0.521 \pm 0.020$ & 3.8 & 104.2 \\
\hline \multicolumn{4}{|l|}{ 2,6-Chlorophenol } \\
\hline 0.02 & $0.0198 \pm 0.0015$ & 7.6 & 99.0 \\
\hline 0.1 & $0.0986 \pm 0.0043$ & 4.4 & 98.6 \\
\hline 0.5 & $0.504 \pm 0.018$ & 3.6 & 100.8 \\
\hline \multicolumn{4}{|l|}{ 2,4-Chlorophenol } \\
\hline 0.02 & $0.0204 \pm 0.0014$ & 6.8 & 102.0 \\
\hline 0.1 & $0.0984 \pm 0.0034$ & 3.5 & 98.4 \\
\hline 0.5 & $0.512 \pm 0.014$ & 2.7 & 102.4 \\
\hline \multicolumn{4}{|l|}{ 2,4,6-Trichlorophenol } \\
\hline 0.1 & $0.102 \pm 0.007$ & 6.9 & 102.0 \\
\hline 0.5 & $0.498 \pm 0.015$ & 3.0 & 99.6 \\
\hline
\end{tabular}


Table 3. Inter-day assay reproducibility for determination of phenol and chlorophenols.

\begin{tabular}{|c|c|c|c|}
\hline Compounds (mg/L) & Measured (mg/L, Mean \pm S.D., $n=5$ ) & C.V. (\%) & Recovery (\%) \\
\hline \multicolumn{4}{|l|}{ Phenol } \\
\hline 0.02 & $0.0191 \pm 0.0017$ & 8.9 & 95.5 \\
\hline 0.1 & $0.0966 \pm 0.0061$ & 6.3 & 96.6 \\
\hline 0.5 & $0.525 \pm 0.028$ & 5.3 & 105.0 \\
\hline \multicolumn{4}{|l|}{ 2-Chlorophenol } \\
\hline 0.02 & $0.0208 \pm 0.0017$ & 8.2 & 104.0 \\
\hline 0.1 & $0.0972 \pm 0.0070$ & 7.2 & 97.2 \\
\hline 0.5 & $0.482 \pm 0.022$ & 4.6 & 96.4 \\
\hline \multicolumn{4}{|l|}{ 4-Chlorophenol } \\
\hline 0.02 & $0.0206 \pm 0.0016$ & 7.8 & 103.0 \\
\hline 0.1 & $0.103 \pm 0.007$ & 6.8 & 103.0 \\
\hline 0.5 & $0.486 \pm 0.027$ & 5.6 & 97.2 \\
\hline \multicolumn{4}{|l|}{ 2,6-Dichlorophenol } \\
\hline 0.02 & $0.0198 \pm 0.0016$ & 8.1 & 99.0 \\
\hline 0.1 & $0.0976 \pm 0.0052$ & 5.3 & 97.6 \\
\hline 0.5 & $0.514 \pm 0.022$ & 4.3 & 102.8 \\
\hline \multicolumn{4}{|l|}{ 2,4-Dichlorophenol } \\
\hline 0.02 & $0.0208 \pm 0.0015$ & 7.2 & 104.0 \\
\hline 0.1 & $0.0984 \pm 0.0065$ & 6.6 & 98.4 \\
\hline 0.5 & $0.512 \pm 0.024$ & 4.7 & 102.4 \\
\hline \multicolumn{4}{|l|}{ 2,4,6-Trichlorophenol } \\
\hline 0.1 & $0.104 \pm 0.009$ & 8.7 & 104.0 \\
\hline 0.5 & $0.493 \pm 0.022$ & 4.5 & 98.6 \\
\hline
\end{tabular}

\subsection{Environmental Analysis}

Tap water samples were collected from the laboratory, and the proposed method was employed to determine phenol and chlorophenols in spiked tap water. As shown in Table 4, phenol and chlorophenols in tap water samples were below the lower limits of quantification in unspiked samples. Calibration curves prepared from tap water samples spiked with the six compounds showed a linear relationship between concentration and peak response, with $r^{2} \geq 0.9933$. The slopes of the calibration curves were similar to those of the standard calibration curves, and the relative recovery values were $89.8 \%$ to $111.0 \%$. These results indicate that our method is capable of monitoring very low levels of contamination with phenol and chlorophenols in tap water.

\section{Conclusion}

A simple HPLC-UV method for simultaneous determination of phenol and chlorophenols in water was previously developed using NBD-F or benzoyl chloride as the derivatizing reagent, without complicated sample clean-up [4] [20]. Here, to improve the sensitivity, we developed an HPLC-FLD system (column size; $50 \times 2.1$ $\mathrm{mm}$ i.d.) using DMEQ-COCl as a fluorescence labeling reagent. This method was simple, reproducible, and sufficiently sensitive to establish whether or not tap water was contaminated with phenol, 2-chlorophenol, 4-chloro- 
Table 4. Levels of phenol and chlorophenols in tap water, and the relative recovery.

\begin{tabular}{cccc}
\hline Compounds & Concentration in tap water sample & Relative recovery (\%, mean \pm S.D., $\mathrm{n}=5)$ & $r^{2}$ (Average) \\
\hline Phenol & N.D. & $89.8 \pm 6.1$ & 0.9933 \\
2-Chlorophenol & N.D. & $92.6 \pm 6.6$ & 0.9946 \\
4-Chlorophenol & N.D. & $94.2 \pm 5.6$ & 0.9971 \\
2,6-Dichlorophenol & N.D. & $92.4 \pm 6.6$ & 0.9972 \\
2,4-Dichlorophenol & N.D. & $106.8 \pm 7.4$ & 0.9965 \\
2,4,6-Trichlorophenol & N.D. & $111.0 \pm 6.9$ & 0.9942 \\
\hline
\end{tabular}

N.D.: not determined.

phenol, 2,4-dichlorophenol, 2,6-dichlorophenol, and 2,4,6-trichlorophenol (i.e. whether or not these compounds were present in excess of regulatory levels).

\section{References}

[1] World Health Organization (2006) Guidelines for Drinking-Water Quality Incorporating First Addendum. Vol. 1, 3rd Edition, WHO, 329-331.

[2] Llompart, M., Lourido, M., Landin, P., García-Jares, C. and Cela, R. (2002) Optimization of a Derivatization-SolidPhase Microextraction Method for the Analysis of Thirty Phenolic Pollutants in Water Samples. Journal of Chromatography A, 963, 137-148. http://dx.doi.org/10.1016/S0021-9673(02)00646-5

[3] González-Toledo, E., Prat, M.D. and Alpendurada, M.F. (2001) Solid-Phase Microextraction Coupled to Liquid Chromatography for the Analysis of Phenolic Compounds in Water. Journal of Chromatography A, 923, 45-52. http://dx.doi.org/10.1016/S0021-9673(01)00975-X

[4] Asan, A. and Isildak, I. (2003) Determination of Major Phenolic Compounds in Water by Reversed-Phase Liquid Chromatography after Pre-Column Derivatization with Benzoyl Chloride. Journal of Chromatography A, 988, 145149. http://dx.doi.org/10.1016/S0021-9673(02)02056-3

[5] Farino, J., Norwitz, G., Boyko, W.J. and Keliher, P.N. (1981) Study of the Behaviour of Various Phenolic Compounds in the 4-Aminoantipyrine and Ultraviolet-Ratio Spectrophotometric Methods without and with Distillation. Talanta, 28, 705-708. http://dx.doi.org/10.1016/0039-9140(81)80104-X

[6] Rodriguez-Alcala, M., Yañez-Sedeño, P. and Diez, L.M. (1988) Determination of Pentachlorophenol by Flow-Injection Analysis with Spectrophotometric Detection.Talanta, 35, 601-604. http://dx.doi.org/10.1016/0039-9140(88)80140-1

[7] Ito, R., Kawaguchi, M., Honda, H., Koganei, Y., Okanouchi, N., Sakui, N., Saito, K. and Nakazawa, H. (2008) Hollow-Fiber-Supported Liquid Phase Microextraction with in Situ Derivatization and Gas Chromatography-Mass Spectrometry for Determination of Chlorophenols in Human Urine Samples. Journal of Chromatography B, 872, 63-67. http://dx.doi.org/10.1016/j.jchromb.2008.07.008

[8] Almeda, S., Nozal, L., Arce, L. and Valcárcel, M. (2007) Direct Determination of Chlorophenols Present in Liquid Samples by Using a Supported Liquid Membrane Coupled in-Line with Capillary Electrophoresis Equipment. Analytica Chimica Acta, 587, 97-103. http://dx.doi.org/10.1016/j.aca.2007.01.035

[9] Tsukagoshi, K., Kameda, T., Yamamoto, M. and Nakajima, R. (2002) Separation and Determination of Phenolic Compounds by Capillary Electrophoresis with Chemiluminescence Detection. Journal of Chromatography A, 978, 213-220. http://dx.doi.org/10.1016/S0021-9673(02)01408-5

[10] Suliman, F.E., Al-Kindi, S.S., Al-Kindy, S.M. and Al-Lawati, H.A. (2006) Analysis of Phenols in Water by HighPerformance Liquid Chromatography Using Coumarin-6-Sulfonyl Chloride as a Fluorogenicprecolumn Label. Journal of Chromatography A, 1101, 179-184. http://dx.doi.org/10.1016/j.chroma.2005.09.094

[11] Ruiz-Jiménez, J. and de Castro, M.D.L. (2007) In-Column micro-High-Performance Liquid Chromatographic Concentration-Separation Prior to Ultraviolet Detection for the Determination of Chlorophenols in Water Samples. Journal of Chromatography A, 1174, 78-84. http://dx.doi.org/10.1016/j.chroma.2007.06.060

[12] Fattahi, N., Assadi, Y., Hosseini, M.R. and Jahromi, E.Z. (2007) Determination of Chlorophenols in Water Samples Using Simultaneous Dispersive Liquid-Liquid Microextraction and Derivatization Followed by Gas Chromatography-Electron-Capture Detection. Journal of Chromatography A, 1157, 23-29. http://dx.doi.org/10.1016/j.chroma.2007.04.062 
[13] Wada, M., Kinoshita, S., Itayama, Y., Kuroda, N. and Nakashima, K. (1999) Sensitive High-Performance Liquid Chromatographic Determination with Fluorescence Detection of Phenol and Chlorophenols with 4-(4,5-Diphenyl-1Himidazol-2-yl)benzoyl Chloride as a Labeling Reagent. Journal of Chromatography B, 721, 179-186. http://dx.doi.org/10.1016/S0378-4347(98)00499-X

[14] Imai, K. (2003) Analytical Chemical Studies on High-Performance Recognition and Detection of Bio-Molecules in Life. Yakugaku Zasshi, 123, 901-917. http://dx.doi.org/10.1248/yakushi.123.901

[15] Higashi, Y., Nakamura, S., Matsumura, H. and Fujii, Y. (2006) Simultaneous Liquid Chromatographic Assay of Amantadine and Its Four Related Compounds in Phosphate-Buffered Saline Using 4-Fluoro-7-nitro-2,1,3-benzoxadiazole as a Fluorescent Derivatization Reagent. Biomedical Chromatography, 20, 423-428. http://dx.doi.org/10.1002/bmc.577

[16] Higashi, Y., Sakata, M. and Fujii, Y. (2007) Simultaneous Determination of the N-Dealkylated Metabolites of Four Butyrophenone-Type Agents in Rat Plasma by HPLC with Fluorescence Detection after Precolumn Derivatization with 4-Fluoro-7-nitro-2,1,3-benzoxadiazole. Journal of Liquid Chromatography \& Related Technologies, 30, 2747-2754. http://dx.doi.org/10.1080/10826070701560850

[17] Fukushima, T., Kawai, J., Imai, K. and Toyo’oka, T. (2004) Simultaneous Determination of D- and L-Serine in Rat Brain Microdialysis Sample Using a Column-Switching HPLC with Fluorimetric Detection. Biomedical Chromatography, 18, 813-819. http://dx.doi.org/10.1002/bmc.394

[18] Higashi, Y., Gao, R. and Fujii, Y. (2009) Determination of Fluoxetine and Norfluoxetine in Human Serum and Urine by HPLC Using a Cholester Column with Fluorescence Detection. Journal of Liquid Chromatography \& Related Technologies, 32, 1141-1151. http://dx.doi.org/10.1080/10826070902841844

[19] Toyo’oka, T., Mantani, T. and Kato, M. (2003) Characterization of Labelling and De-Labelling Reagents for Detection and Recovery of Tyrosine Residue in Peptide. Biomedical Chromatography, 17, 133-142. http://dx.doi.org/10.1002/bmc.223

[20] Higashi, Y. and Fujii, Y. (2009) HPLC-UV Analysis of Phenol and Chlorophenols in Water after Pre-Column Derivatization with 4-Fluoro-7-nitro-2,1,3-benzoxadiazole. Journal of Liquid Chromatography \& Related Technologies, 32, 2372-2383. http://dx.doi.org/10.1080/10826070903188013 